\title{
Cerebral Abscess after Transrectal Needle Biopsy of the Prostate: A Case Report and Review of the Literature
}

\author{
Ebru Erdal Wasim Mahmalji Zahoor Fazili Howard P. Marsh Shikohe Masood
}

Department of Urology, Medway Foundation Trust Hospital, Gillingham Kent, UK

\section{Key Words}

Cerebral abscess $\cdot$ Prostate $\cdot$ Biopsy

\begin{abstract}
Transrectal ultrasound-guided prostate biopsy is widely used for the diagnosis of prostate cancer. Although considered a safe procedure it is associated with complications which can be hemorrhagic (hematuria, hematospermia and hematochezia) or infective (bacteremia, bacteriuria, urinary tract infection, pyrexia and sepsis). We present a previously unreported complication of transrectal biopsy of the prostate, cerebral abscess in an otherwise healthy 54-year-old male with suspected prostate cancer. This case report highlights the need for awareness of infective complications in this seemingly safe procedure.
\end{abstract}

Copyright $\odot 2011$ S. Karger AG, Basel

\section{Case Report}

A healthy 54-year-old gentleman underwent transrectal ultrasound-guided prostate biopsy (TRUSPB) because of his raised age specific prostate specific antigen level $(3.9 \mathrm{ng} / \mathrm{l})$. He received antibiotic prophylaxis with one dose of oral ciprofloxacin $500 \mathrm{mg}$ prior to the procedure to be continued twice daily for 3 days. The biopsy was uneventful.

\section{KARGER}

Fax +4161306 1234

E-Mail karger@karger.ch

www.karger.com
(C) 2011 S. Karger AG, Basel

1015-9770/11/0054-0216\$26.00/0

Accessible online at:

www.karger.com/cur
Two days later he was re-admitted to hospital with a 24-hour history of nausea, vomiting and diarrhea. On admission he was apyrexial but hypotensive. On examination he was dehydrated and had mild neck stiffness. His white blood cell count was $24.1 \times 10^{9} /$ 1 (normal range $3.8-5.8 \times 10^{\circ} / \mathrm{l}$ ) and C-reactive protein $333 \mathrm{mg} / \mathrm{l}$ (normal range $0-5 \mathrm{mg} / \mathrm{l}$ ). Blood and urine cultures were taken and IV gentamicin $5 \mathrm{mg} / \mathrm{kg}$ and metronidazole $500 \mathrm{mg}$ was started 3 times daily, this was later changed to tazocin and gentamicin on microbiology advice.

Although there was an initial improvement in white blood cell and C-reactive protein; he became confused with a Glasgow coma scale score of 10 with neck stiffness, photophobia and upper motor neurone signs. A head computed tomography revealed no pathology; a lumbar puncture was not performed due to thrombocytopenia. A working diagnosis of $E$. coli associated meningitis with sepsis or cerebral sinus venous thrombosis was made by the neurosurgeons and the patient continued with tazocin and gentamicin. Despite this his Glasgow coma scale score dropped to 6 and he was intubated and transferred to the intensive treatment unit.

An magnetic resonance imaging brain (fig. 1, 2) revealed multifocal lesions in both cerebral hemispheres, as well as in the left midbrain, thought to represent multiple abscesses, most likely caused by E. coli meningitis.

Blood culture sensitivity reports showed the $E$. coli to be an extended spectrum beta-lactam organism resistant to tazocin and gentamicin but sensitive to meropenem and amikacin. Antibiotic therapy with meropenem was commenced; the patient improved and was extubated after 6 days.

After 10 days in intensive treatment unit the patient was moved to the stroke unit and then referred to a neuro-rehabilitation centre where he made a slow but gradual recovery. On follow-up he continues to have some cognitive and perceptual deficits. Histology showed benign prostatic hyperplasia with no cancer.

Wasim Mahmalji

Department of Urology

Medway Foundation Trust Hospital

ME7 5NY Gillingham Kent (UK)

Tel. +44 01634830 000, Fax +44 01634 845649, E-Mail dr_wasim@hotmail.co.uk 


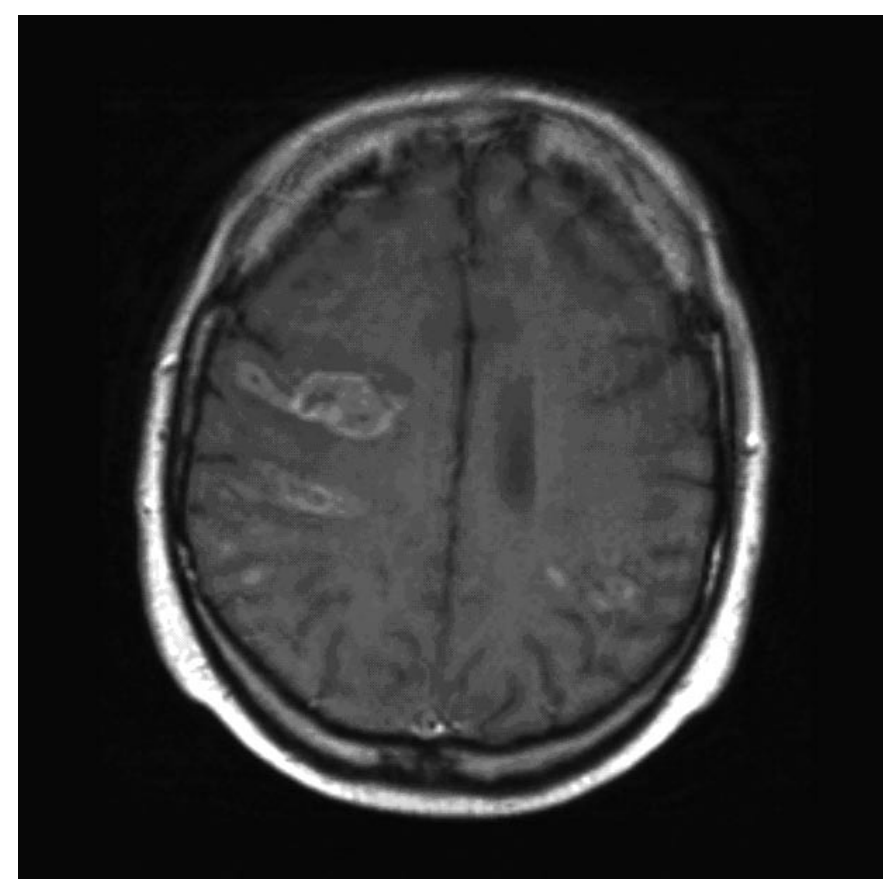

Fig. 1. Axial enhanced MRI image showing multi-focal ring enhancing lesions some of which are confluent.

\section{Discussion}

We present a very unusual complication of TRUSPB which has not previously been reported in the literature. Prostate biopsy is generally considered safe and is carried out under local anesthesia as an outpatient procedure. Severe post biopsy infections have been reported in less than $1 \%$ of cases.

In the United Kingdom, antibiotic prophylaxis is not standardized with many different regimes in use [1]. In America Shandera et al. [2] surveyed 568 urologists and found over $90 \%$ use fluoroquinolones either alone or in combination with another antibiotic as prophylaxis. Quinolones, such as ciprofloxacin are considered to be effective prophylactics as urosepsis rates are low [3]. This is due to its broad spectrum action effectiveness in treating common urinary and colorectal flora and high concentration in the prostate tissue.

In a study of 1,000 biopsies Sieber et al. [4] found that only 3 patients developed urinary tract infections (UTI). Kakehi et al. [5] reported in 2008 that of 212,065 TRUSPB the incidence of fever and sepsis were 1.1 and $0.07 \%$, where levofloxacin was used as prophylaxis. However,

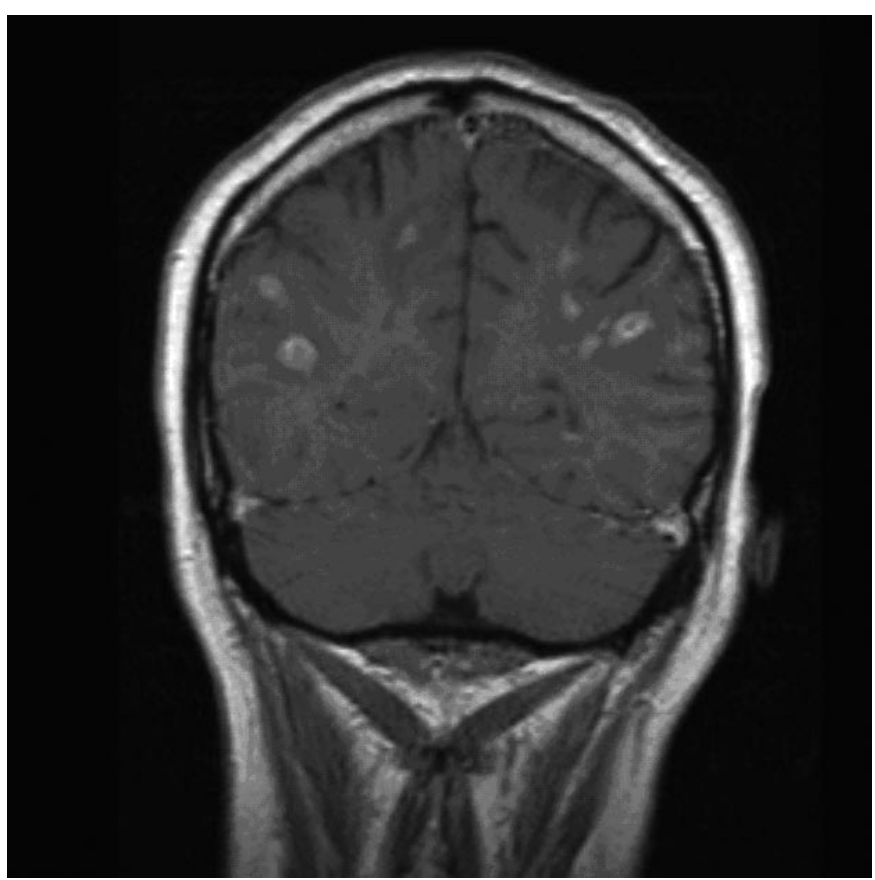

Fig. 2. Coronal enhanced MRI image showing multi-focal ring enhancing lesions some of which are confluent.

they reported 1 death due to sepsis caused by fluoroquinolone-resistant E.coli. Miura et al. [6] reported 4 cases of post-TRUSPB sepsis from fluoroquinolone-resistant E.coli, a rate of $0.6 \%$, between July 2002 and December 2006.

The rate of bacterial resistance to antibiotics and hospital admission due to infection related complications is increasing. In a study of 75,190 prostate biopsies between 1996 and 2005, Nam et al. [7] found the 30-day hospital admission rate increased from $1 \%$ in 1996 to $4.1 \%$ in $2005,72 \%$ of which were due to infective complications.

The prevalence of fluoroquinolone resistant strains of E.coli and particularly extended spectrum beta-lactam is also increasing. In the United Kingdom resistance to ciprofloxacin has increased from $13 \%$ in 2003 to $23 \%$ in 2007 [8]. Feliciano et al. [9] evaluated the record of 1,273 patients who had TRUSPB between January 2004 and December 2006 and found that infective complications were 3 times higher in 2006 compared to 2004 and 2005. They also noted that the incidence of fluoroquinolone resistant UTI was 4.3 and 3.3 times higher in 2006 compared to that in 2004 and 2005 respectively. 
So whilst quinolones are the antibiotic of choice given their broad spectrum cover, they may be ineffective against multi-resistant micro-organisms.

We recommend always considering carefully if the biopsy is needed, especially in older men and those with multiple co-morbidities. In a study by Miura et al. [6], 3 out of 4 of those who had sepsis due to biopsy had benign disease and 1 had prostate intraepithelial neoplasia.

Secondly, consider the choice of antibiotic in those who have a past history of UTI or sepsis with a quinolone resistant organism who may be more at risk of post biopsy infection.
Individuals should be asked if they work in healthcare. Kamdar et al. [10] reported 3 out of the 4 patients who developed multi-drug resistant bacteremia following biopsy between November 2006 and November 2007, worked in a hospital or had a hospital-related contact.

Our case report re-enforces the need to evaluate the reasons for undertaking TRUSPB and the risk associated with biopsy, as it reminds us of the serious complications that may occur as a result of this simple and routine procedure. Bacterial meningitis post TRUSPB has been reported but not a cerebral abscess [11].

\section{References}

$>1$ Patel HR, Lee F, Arya M, Masood S, Palmer JH, Sheriff MK: A national survey of transrectal ultrasound-guided prostatic biopsies: time for a national guideline. Int J Clin Pract 2003;57:773-774.

$>2$ Shandera KC, Thibault GP, Deshon GE Jr: Variability in patient preparation for prostate biopsy among American urologists. Urology 1998;52:644-646.

3 Lange D, Zappavigna C, Hamidizadeh R, Goldenberg SL, Paterson RF, Chew BH: Bacterial sepsis after prostate biopsy-a new perspective. Urology 2009;74:1200-1205.

$\checkmark 4$ Sieber PR, Rommel FM, Theodoran CG, Hong RD, Del Terzo MA: Contemporary prostate biopsy complication rates in community-based urology practice. Urology 2007;70:498-500.
Kakehi Y, Naito S: Complication rates of ultrasound-guided prostate biopsy: a nationwide survey in Japan. Int J Urol 2008;15:319_ 321.

-6 Miura T, Tanaka K, Shigemura K, Nakano Y, Takenaka A, Fujisawa M: Levofloxacin resistant Escherichia coli sepsis following an ultrasound-guided transrectal prostate biopsy: Report of four cases and review of the literature. Int J Urol 2008;15:457-459.

$>7$ Nam RK, Saskin R, Lee Y, Liu Y, Law C, Klotz LH, Loblaw DA, Trachtenberg J, Stanimirovic A, Simor AE, Seth A, Urbach DR, Narod SA: Increasing hospital admission rates for urological complications after transrectal ultrasound guided prostate biopsy. J Urol 2010;183:963-968.
8 http://www.hpa.org.uk/web/HPAwebFile/ HPAweb_C/1222327087329.

$\checkmark 9$ Feliciano J, Teper E, Ferrandino M, Macchia RJ, Blank W, Grunberger I, Colon I: The incidence of fluoroquinolones resistant infections after prostate biopsy-are fluoroquinolones still effective prophylaxis? J Urol 2008;179:952-955.

10 Kamdar C, Mooppan UM, Gulmi FA, Kim $\mathrm{H}$ : Multi-drug-resistant bacteremia after transrectal ultrasound guided prostate biopsies in hospital employees and their relatives. Urology 2008;72:34-36.

11 Tufan ZK, Bulut C, Yazan T, Hatipoglu C, Erdinc S, Kinikli S, Demiroz AP: A lifethreatening Escherichia coli meningitis after prostate biopsy. Urol J 2011;8:69-71. 